\title{
Introducing Tech TIME: Online Quick References for Nuclear Medicine Technologists
}

\author{
LisaAnn Trembath, CNMT, MSM, CCRA, FSNMTS ${ }^{1}$ and Dawn Holley, CNMT, RT(N)(CT) ${ }^{2}$ \\ ${ }^{I}$ Avid Radiopharmaceuticals, Inc., Philadelphia, Pennsylvania; and ${ }^{2}$ Stanford University, Stanford, California
}

\begin{abstract}
J Nucl Med Technol 2018; 46:24-25
DOI: $10.2967 /$ jnmt.117.204974
\end{abstract}

\section{INTRODUCING TECH TIME}

The information superhighway provides nearly instant instructions for almost anything one may wish to do or learn. Need to fix a kitchen sink? YouTube videos will walk you through it. Wondering who won the World Series in 1922? A quick online search provides all you need to know with a few keystrokes. Even nuclear medicine and PET concepts and terms can be accessed with an internet connection and a browser. Information for patients is readily available in answer to questions such as "What is a PET scan?" and "How much radiation is there in a nuclear medicine scan?" If you google "PET imaging," you will find personal stories from patients, videos that show a patient being scanned, and scientific explanations of PET imaging from experts. If one had time to spare, sitting with a search engine and keyboard could produce a lot of information about PET imaging. But even with a huge volume of facts and figures available online, until now there hasn't been a specific location for technologists to quickly look up how to position the head for optimal brain PET or refresh their memory about the correct uptake time for an amyloid PET scan. And if a search resulted in information that could help, would a technologist have confidence that it is accurate and up to date?

The Tech TIME (Technical Imaging Multidisciplinary Education) series has been created by the Technologist Section of the Society of Nuclear Medicine and Molecular Imaging (SNMMI-TS) to address the information gap between traditional continuing education and immediately available online reference materials. Envisioned by Past SNMMI-TS President Sara G. Johnson and implemented under SNMMI-TS President Kathleen Krisak, the goal of the Tech TIME task

Received Nov. 8, 2017; revision accepted Nov. 28, 2017.

For correspondence or reprints contact: LisaAnn Trembath, CNMT, MSM, CCRA, FSNMTS, Avid Radiopharmaceuticals, 3711 Market St., Philadelphia, PA 19104.

E-mail: Trembath@avidrp.com

COPYRIGHT (c) 2018 by the Society of Nuclear Medicine and Molecular Imaging. force is to create accurate and up-to-date online tools to quickly answer questions and solve problems in the daily workplace. The tools provided in the Tech TIME series come in the form of fact sheets that can be easily read or downloaded from the SNMMI website, short (2-3 min) videos to answer specific how-to questions, case studies with relevant patient examples, and lists of resources for follow-up learning or continuing education credit if desired.

The task force that evolved into the Tech TIME project was initially funded in late 2016 by a partnering agreement between the SNMMI-TS and Eli Lilly \& Co. to create noncredit training and informational tools about PET brain imaging specifically for technologists. The task force recognized that brain imaging has not been widely performed in the United States and technologists may need access to more than traditional continuing education symposia. The first project undertaken by the task force was to create fact sheets for ${ }^{18} \mathrm{~F}-\mathrm{FDG}$ brain PET, amyloid brain PET, and other neurology procedures in nuclear medicine. These fact sheets can be quickly accessed on the SNMMI website and provide basic but relevant information for someone who needs to refresh on dosing, administration, contraindications, and basic acquisition and processing. Another fact sheet describes key reimbursement tips for ${ }^{18} \mathrm{~F}-\mathrm{FDG}$ PET imaging and amyloid PET in dementia, both of which are reimbursed by the Centers for Medicare \& Medicaid Services only under specific conditions. The task force also put together some case studies with diagnostic dilemmas and how PET imaging helped to direct clinical treatment. These case studies are available for download on the SNMMI website in an Adobe brochure format or as a set of PowerPoint slides.

At the time of this writing, the task force is also in the process of developing short videos on very specific questions related to brain imaging, such as how to position the head for brain PET, optimizing patient preparation for ${ }^{18} \mathrm{~F}-\mathrm{FDG}$ and amyloid PET, appropriate pre- and postinjection conditions for ${ }^{18} \mathrm{~F}-\mathrm{FDG}$, choosing the correct uptake and scanning time for amyloid PET radiopharmaceuticals, and scan acquisition and processing, as well as common questions from patients and caregivers. A technologist could access these videos from a laptop, smart phone, or tablet.

As the task force worked on developing new tools for brain imaging, group members began to discuss using the same strategy for other nuclear medicine and PET studies, such as cardiac or oncology. The name Tech TIME was 
proposed as an umbrella name for the strategy to provide practical and relevant reference materials as a supplement to traditional continuing education programs.

The Tech TIME strategy aligns with current understanding of adult learning principles. Experts in education tell us that adult learners need information that can be immediately applied to their professional needs, improve their skills, and facilitate their daily work. Successful adult learning is problem-centered rather than content-oriented (1). Tech TIME tools are oriented to the problems of scanning technologists who face new procedures and patient situations, often without the benefit of attending meetings or reading journal articles. Tools from Tech TIME are not intended to replace traditional continuing education, but rather to enhance it by serving as quick references and facilitating immediately applicable learnings.
Members of the Brain Tech TIME task force are Dawn Holley (co-chair), LisaAnn Trembath (co-chair), Shelley Acuff, Dmitry Beyder, Christopher Blanton, Lance Burrell, Stacy Copley, Michael Czachowki, Linda Davidge, Rhea Anne Davis, Courtney Ducker, Laura Hanson, Lyndsi Hay, Sara Johnson, Kathleen Krisak, Leesa Ann Ross, Kiran K. Solingapuram Sai, and Michelle Wanner. Technologists who are interested in contributing to a Tech TIME project should email Nikki Wenzel-Lamb at NWenzel-Lamb@snmmi.org for more information.

\section{REFERENCE}

1. Pappas C. The adult learning theory—andragogy—of Malcolm Knowles. eLearning Industry website. https://elearningindustry.com/the-adult-learning-theory-andragogyof-malcolm-knowles. May 9, 2013. Accessed January 8, 2018. 